\title{
Primary diagnosis, survival and long-term outcome in young horses with problems in the neonatal period
}

\author{
Franziska Palm ${ }^{7}$, Christine Aurich², Imke Nachengast' and Jörg Aurich ${ }^{7}$ \\ Section for Obstetrics, Gynecology and Andrology ${ }^{1}$ and Centre for Artificial Insemination and Embryo Transfer ${ }^{2}$, University of Veterinary Sciences, \\ Vienna, Austria
}

\begin{abstract}
Summary
In this study, neonatal disorders of foals in a referral hospital $(n=170)$, survival and further development until the age of at least three years were analysed retrospectively. The most frequent primary diagnosis was septicemia (33\%), followed by prematurity (16\%), failure of passive transfer (FPT; 13\%) and gastro-intestinal problems (8\%). Out of 170 foals, 108 survived and were discharged healthy. Survival rate was lowest in premature neonates (22\%) and foals with septicemia (55\%). In all other groups $>80 \%$ of the foals survived and were discharged healthy. The frequency of primary diagnoses did not differ between female and male foals. Only in cases with meconium impaction, statistical significance was nearly reached ( 2 female, 9 male, $p=0.06$ ). Pronounced deviations from normal clinical and laboratory values were mainly found in premature foals (e.g. decreased body temperature, prolonged capillary refill time, immature blood count). For 70 foals, information on development up to an age of at least 3 years was available. Out of these, 42 had been healthy during at least 3 years after treatment in the neonatal period. A variety of problems were reported in the remaining 28 foals.
\end{abstract}

Keywords: foal / neonatal disorders / prematurity / septicemia / survival

\section{Diagnose, Überleben und weitere Entwicklung von jungen Pferden mit kritischen Problemen in der Neugeborenenphase}

In dieser Arbeit wurden die Erstdiagnosen, die Überlebensrate und die weitere Entwicklung bis zum Alter von 3 Jahren bei Fohlen ( $\mathrm{n}=170$ ) analysiert, die in der Neugeborenenphase in einer Überweisungsklinik behandelt wurden. Die häufigsten Diagnosen waren Septikämie (33\%), Unreife (16\%), ungenügende Immunglobulinversorgung (FPT; 13\%) und gastro-intestinale Probleme (8\%). Von 170 Fohlen, überlebten 108 und wurden gesund aus der Klinik entlassen. Die Überlebensrate war bei unreifen Fohlen am geringsten (22\%), gefolgt von Fohlen mit Septikämie (55\%). In allen anderen Gruppen wurden $>80 \%$ der Fohlen gesund entlassen. Hinsichtlich der Diagnosen gab es keine signifikanten Geschlechtsunterschiede, bei Fohlen mit Mekoniumverhaltung wurde eine statistische Signifikanz aber annähernd erreicht (2 Stutfohlen, 9 Hengstfohlen, $p=0.06$ ). Deutliche Veränderungen klinischer und labordiagnostischer Parameter lagen vor allem bei unreifen Fohlen vor (z.B. erniedrigte innere Körpertemperatur, verlängerte kapilläre Füllungszeit, unreifes Blutbild). Für 70 Fohlen lagen Informationen über die weitere Entwicklung vor. Von diesen, waren 42 bis zum Alter von mindestens 3 Jahren gesund. Verschiedene, jedoch nicht immer zwangsläufig auf die neonatalen Probleme zurückzuführende Erkrankungen traten bei den übrigen 28 Fohlen auf.

Schlüsselwörter: Fohlen / Neugeborenenphase / Unreife / Septikämie / Überlebensrate / Neonatologie

\section{Introduction}

Despite major advances in equine perinatology in the 1980ies and 90ies (e.g. Koterba and Brewer 1984, LeBlanc et al. 1992, Sanchez 2005), diseases in the neonatal period are still a considerable threat for survival and well-being of foals after birth. No recent survey is available on neonatal diseases in foals and the situation in Austrian horse breeding has not been analysed so far. Austria is a country without a larger-scale professional horse breeding industry and virtually no Thoroughbred racehorse breeding. With regard to stud farm management and attitude of horse owners it may thus differ from countries where a large number of horses are bred in rather circumscribed areas such as parts of Kentucky, California, Newmarket region, Northern Germany, Netherlands or Ireland.

In this study, neonatal disorders in foals referred to the Section for Obstetrics, Gynecology and Andrology at the Animal Hospital of the Vienna University of Veterinary Sciences from 2004 to 2008, survival rate as well as further development until the age of at least three years were analysed retrospectively. Specific questions were whether the spectrum of disor- ders has changed compared to older reports, whether survival rate and subsequent health of the horses has improved and whether the equine neonatology caseload in Austria differs from other countries.

\section{Animals, Materials and Methods}

Animals

For this study, all sick foals presented to the Section for Obstetrics, Gynecology and Andrology of the Vienna University of Veterinary Sciences between 2004 and 2008 were evaluated. Healthy foals born to mares hospitalized for surveillance of foaling were not included into the study. For analysis, foals were divided by age group (0-7 days, 8-14 days, 15-21 days old on admittance to the clinic), gender and primary clinical diagnosis (Table 1). Secondary problems developing after admittance to the clinic were not considered for classification of the foals. Foals included into the study $(n=170)$ were from the following breeds: warmblood $(n=61)$, trotter $(n=31)$, Quarter Horse $(n=24)$, Arab $(n=16)$, draft horses $(n=7)$, 
Icelandic Horse $(n=8)$, Thoroughbred $(n=5)$, Haflinger $(n=4)$, ponies $(n=4)$ and other breeds $(n=10)$.

\section{Clinical examination}

All foals were submitted to a routine clinical examination (Koterba 1990a). In addition, IgG concentrations were determined from 2004 to 2007 with a semiquantitative test (GammaCheck, Veterinary Immunogenics, Penrith, UK; SnapFoal, IDEXX, Wörrstadt, Germany). In 2008 lgG was measured with a densimeter (Animal Reproductive Systems, Chino, California, USA).

\section{Treatments}

Foals with lgG level $<800 \mathrm{mg} / \mathrm{dl}$ were treated with 1 or $2 \mathrm{~L}$ of commercial hyperimmune serum (Hypermune, Veterinary Immunogenics, Carleton Hill, Penrith, Cumbria, England). Depending on the primary diagnosis, foals were treated with penicillin (20000-40000 IU/kg i.v. 4 times daily; PenicillinG-Natrium, Sandoz, Kundl, Austria) in combination with gentamicin $(6.6 \mathrm{mg} / \mathrm{kg}$ i.v. once daily; Gentavan, Vana, Vienna, Austria) and case-dependent with cephalosporines (Cefquinom $1 \mathrm{mg} / \mathrm{kg}$ i.v. twice daily; Cobactan Equine, Intervet, Oberschleissheim, Germany) or ceftiofur (4.4-10.0 mg/kg i.v. or i.m. twice daily; Excenel, Pfizer, Vienna, Austria). As antiphlogistic treatment flunixin-meglumine was given (1.1 $\mathrm{mg} / \mathrm{kg}$ i.v. twice daily, Finadyne, Essex, Munich, Germany). For stomach protection, omeprazol (Ratiopharm, Vienna, Austria) was used (2-4 mg/kg once daily orally) and in foals with problems of the gastro-intestinal-tract ranitidin was used $(1.5 \mathrm{mg} / \mathrm{kg}$ i.v. 3 times daily, Ulsal, Gebropharm, Fieberbrunn, Austria). Depending on the degree of dehydration, electrolyte imbalances and plasma glucose concentrations, foals were infused with polyionic fluids (Sterofundin, Braun, Melsungen, Germany) or glucose 5\% (Medipharm, Kufstein, Austria). Foals not able to drink were fed mares milk or milk replacer (Pavo Fohlenmilch, Salzburg, Austria) by nasogastric tube.

\section{Development of foals after dismissal from the clinic}

Owners from all surviving foals treated between 2004 and 2007 were interviewed by telephone on the development of their foals until the age of at least 3 years.

\section{Statistical analysis}

Statistical comparisons were made with the PASW 19.0 statistics package (SPSS, Chicago, Illinois, USA). Frequency distributions were analysed by $\mathrm{chi}^{2}$ test. Comparisons between groups were made by Oneway analysis of variance with

Table 1 Definitions for classification of foals by primary clinical diagnosis / Definitionen zur Einteilung der Fohlen anhand der primären klinischen Diagnose

Primary clinical diagnosis

Failure of passive transfer (FPT)

Septicemia

Isolated omphalophlebitis

Asphyxia

Prematurity

Gastro-intestinal tract

Urinary tract

Pneumonia

Orthopedic problems

Malformations

Miscellaneous
Definition and comments

Low plasma lgG concentrations ( $<800 \mathrm{mg} / \mathrm{dl}$ ) at $\leq 24 \mathrm{~h}$ of age and receiving plasma transfusion, no signs of infection and no antibiotic treatment

Clinical signs of infection (petechiae, fever, depression/ coma), history of problems in late pregnancy, at parturition or thereafter, inflammatory changes in hematological parameters, $\lg G$ concentrations $<800 \mathrm{mg} / \mathrm{dl}$ ).

Septicemic foals were further subclassified:

- systemic septicemia without organ manifestation

- mature foals with septicemia due to placentitis

- septicemia and gastro-intestinal-tract (GIT) symptoms (primarily diarrhea)

- septicemia and omphalophlebitis (visible or determined by ultrasound)

- septicemia and pneumonia

- septicemia and arthritis/polyarthritis

Omphalophlebitis not connected to low lgG levels, no systemic clinical signs and slight or no hematological (only fibrinogen elevated)

History of dystocia and/or typical signs of maladjustment

- Premature foals from mares without placentitis: clinical signs of prematurity, immature white blood count (4.500 leucocytes, N/L ratio $\leq 2 / 1)$, immature ossification of carpal and tarsal joints (diagnosis by $\mathrm{x}$-ray).

- Premature foals from mares with placentitis: findings as outlined above but history of placentitis in the mares and increased leucocytes and band nuclei.

Meconium impaction and abdominal distress for other reasons

Rupture of urinary bladder

Pneumonia not connected to low lgG concentrations and/or septicemia

Contracted or relaxed flexor tendons, carpus valgus/varus

Any malformation

Any other problem 
Tukey's test for post-hoc comparisons. A p-value $<0.05$ was considered significant. All data given are means \pm SEM.

\section{Results}

Frequency of primary diagnosis and clinical outcome

By far the most frequent primary diagnosis was septicemia (33\%), followed by prematurity (16\%) and FPT (13\%). Fourteen foals suffered from gastro-intestinal problems (8\%), including 11 foals with meconium impaction, 11 foals (7\%) were diagnosed with orthopedic problems and 10 (6\%) with an isolated umbilical inflammation, i.e. without signs of septicemia (Table 2). Out of the 170 foals, 148 (87\%) were admitted to the clinic within the first week of life and 117 (69\%) out of 170 within the first 48 hours of life. Eleven foals (6.5\%) were admitted in their second and third week of life, respectively.

Out of 170 foals, 108 (64\%) survived and were discharged healthy. Seven out of 8 foals with malformations were euthanized (Atresia coli $n=2$, malformation of the bladder, cleft palate, anophthalmia, tetralogy of Fallot, arthrogryposis $n=1$, each). The one surviving foal had a tail rotation of approximately $360^{\circ}$. In foals without malformations, survival rate was lowest in premature neonates $(22 \%)$ and foals with septicemia (55\%). In all other groups (except miscellaneous) $>80 \%$ of the foals survived and were discharged healthy. All foals with only FPT or with an isolated omphalophlebitis (i.e. without signs of septicemia) survived (Table 2).

From 14 foals with gastro-intestinal tract problems, 2 were euthanized (rupture of the colon, volvulus of small intestine). Eleven foals in this group suffered from meconium impaction and all were treated successfully (8 conservative and 3 surgically). One foal with contracted front limb flexor tendons had to be euthanized because of an open infected joint that had developed before referral to the clinic. Foals with miscellaneous problems included surviving neonates with traumatic lacerations $(n=3)$, rib fractures $(n=3)$, neonatal isoerythrolysis $(n=1)$ and neonates that had to be euthanized because of musculoscelatal malformation due to hyperplasia of the thy- roidea (McLaughlin et al. 1986; $n=3$ ) and widespread detachment of the skin $(n=1)$.

The frequency of primary diagnoses did not differ between female and male foals. Only in cases with meconium impaction, statistical significance was nearly reached (2 female, 9 male, $\mathrm{p}=0.06$, chi $^{2}$-test)

Out of the 170 foals, 9 were referred with contracted flexor tendons of the front legs. These foals did not develop any further problems. However, from the foals with FPT and with septicemia, 8 and 4 foals, respectively, also had contracted tendons. Because FPT or septicemia was considered a life-threatening problem requiring immediate and aggressive treatment, these foals were classified accordingly.

\section{Septicemia and prematurity}

Septicemia and prematurity were the most frequent disorders. FPT is the main reason for septicemia with bacteria often ascending from the umbilicus. Thus foals with septicemia, FPT, isolated omphalophlebitis and premature foals were submitted to a more detailed analysis.

Heart rate, respiratory rate, capillary refill time and temperature in foals with septicemia, FPT, isolated omphalophlebitis and prematurity on arrival at the clinic were largely within the normal range and did not differ between most groups of foals. However, capillary refill time was significantly reduced in premature foals born to mares with placentitis $(p<0.05$ vs. systemic septicemia, septicemia with gastrointestinal manifestations and foals with isolated omphalophlebitis). Body temperature at first examination was significantly reduced in premature foals born to mares without placentitis $(p<0.05$ vs. systemic septicemia, septicemia/arthritis/polyarthritis, septicemia with omphalophlebitis and isolated omphalophlebitis; Figure 1a-d).

Leucocyte numbers were low in premature foals born to mares without placentitis and highest in septic, non-premature foals born after placentitis and in foals with septic arthri-

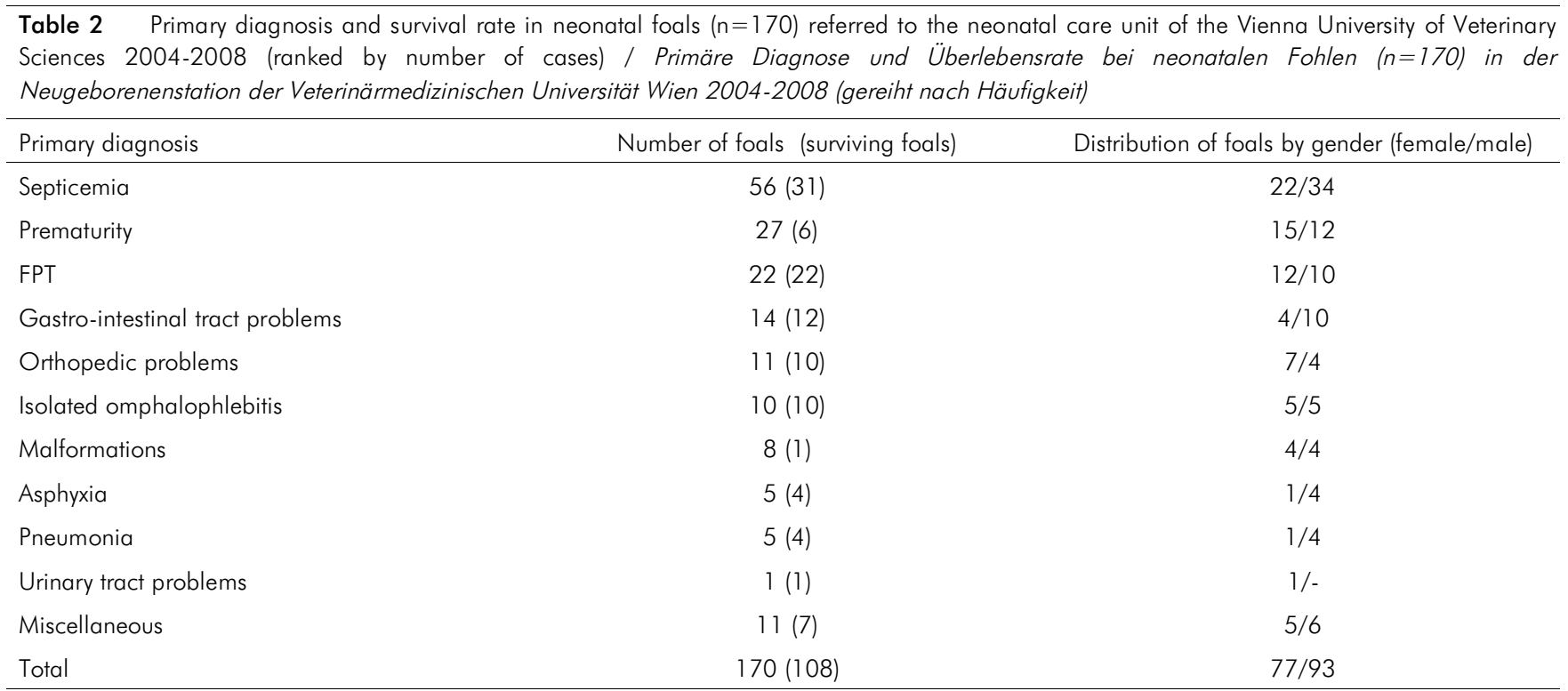


(a)

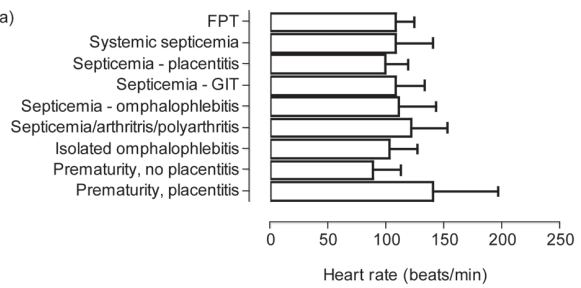

(b) Systemic septicemiaSepticemia - placentitis Septicemia - GIT Septicemia - omphalophlebitis Septicemia/arthritris/polyarthritis Isolated omphalophlebitis Prematurity, placentitis

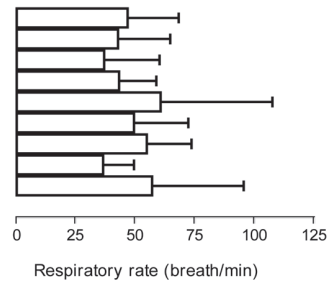

(c)

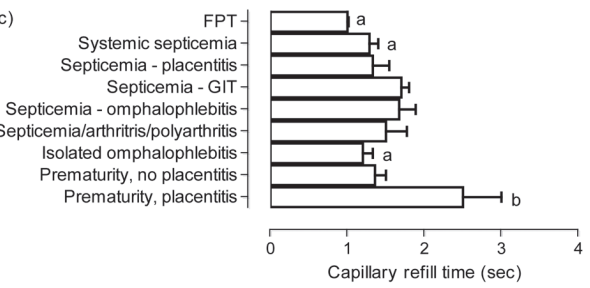

(d)

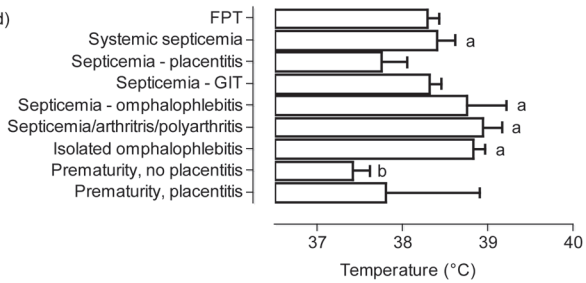

Fig. 1 (a) Heart rate, (b) respiratory rate, (c) capillary refill time and (d) temperature in foals with septicemia, FPT, isolated omphalophlebitis and prematurity on admission to the clinic ( $a, b$ : values with different superscript letters differ significantly, for $n$-numbers see table 3)

(a) Herzfrequenz, (b) Atemfrequenz, (c) kapilläre Füllungszeit und (d) innere Körpertemperatur bei Fohlen mit Septikämie, ungenügender Immunglobulinversorgung (FPT), isolienter Omphalophlebitis und Unreife bei Einlieferung in die Klinik ( $a, b$ : Werte mit unterschiedlichen Indizes unterscheiden sich signifikant, $n$-Zahlen siehe Tabelle 3)

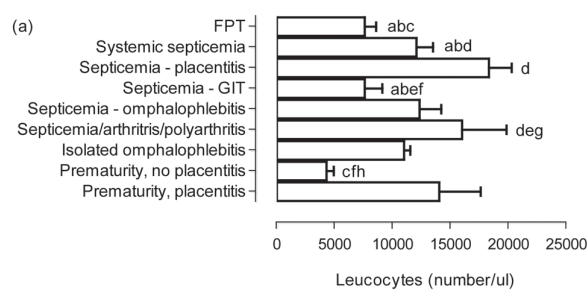

(b)
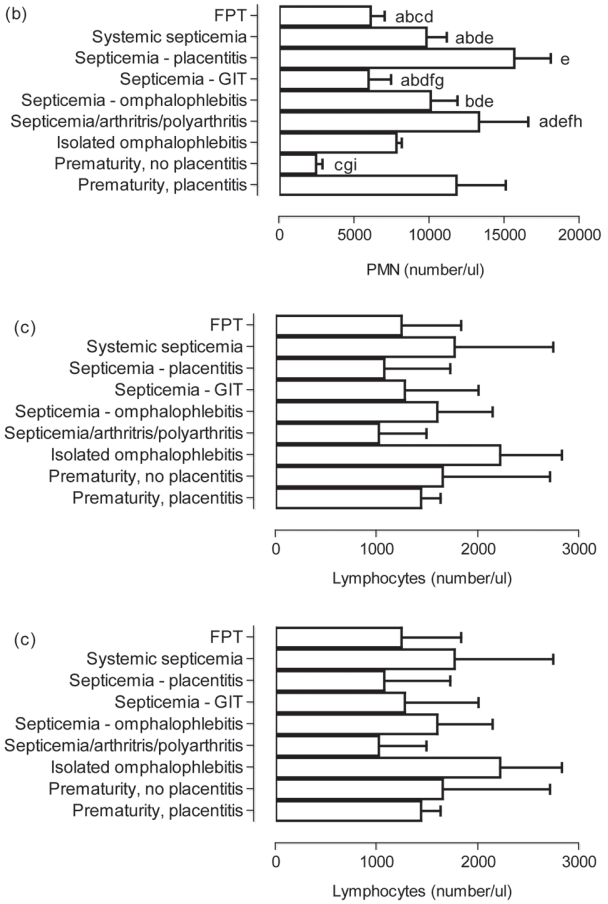

Fig. 2 (a) Leucocyte, (b) PMN, (c) lymphocyte numbers and (d) plasma fibrinogen concentration in foals with septicemia, FPT, isolated omphalophlebitis and prematurity on admission to the clinic (ai: values with different superscript letters differ significantly, for $\mathrm{n}$ numbers see table 3) / Anzahl an (a) Leukozyten, (b) polymorphkernigen neutrophilen Granulozyten (PMN), (c) Lymphozyten und (d) Fibrinogenkonzentration bei Fohlen mit Septikämie, ungenügender Immunglobulinversorgung (FPT), isolienter Omphalophlebitis und Unreife bei Einlieferung in die Klinik (a-i: Werte mit unterschiedlichen Indizes unterscheiden sich signifikant, n-Zahlen siehe Tabelle 3)

Table 3 Number of foals and clinical outcome in foals with septicemia, FPT, isolated omphalophlebitis and prematurity

Anzahl und klinische Entwicklung bei Fohlen mit Septikämie, ungenügender Immunglobulinversorgung (FPT), isolierter Omphalophlebitis und Unreife

\begin{tabular}{lcc}
\hline Primary clinical diagnosis & $\begin{array}{c}\text { Number of foals } \\
\text { (surviving foals) }\end{array}$ & $\begin{array}{c}\text { Distribution of foals by gender } \\
\text { (female/male) }\end{array}$ \\
\hline Failure of passive transfer (FPT) & $22(22)$ & $12 / 10$ \\
Septicemia & $27(16)$ & $13 / 14$ \\
$-\quad$ Systemic septicemia, no organ manifestations & $6(3)$ & $4 / 2$ \\
- Septicemia in mature foals due placentitis ante partum & $7(6)$ & $2 / 5$ \\
- Septicemia and gastro-intestinal tract symptoms & $6(3)$ & $1 / 5$ \\
- Septicemia and omphalophlebitis & $1(0)$ & $0 / 1$ \\
- Septicemia and pneumonia & $9(3)$ & $2 / 7$ \\
- Septicemia/arthritis/polyarthritis & $10(10)$ & $5 / 5$ \\
Isolated omphalophlebitis & & $13 / 11$ \\
Prematurity & $24(6)$ & $2 / 1$ \\
- Prematurity, not linked to placentitis & $3(0)$ & \\
\hline
\end{tabular}




\begin{tabular}{|c|c|c|c|c|c|c|c|c|c|c|c|}
\hline \multicolumn{12}{|l|}{$\begin{array}{l}\text { Problems in surviving foals w } \\
\text { von 3-6 Jahren nach Klinika }\end{array}$} \\
\hline \multirow[b]{2}{*}{$\begin{array}{l}\text { Problems after neonatal hospitalisation } \\
\text { reported by owners }\end{array}$} & \multirow[b]{2}{*}{$\begin{array}{c}\text { Total } \\
(n=28)\end{array}$} & \multicolumn{10}{|c|}{ Primary diagnosis of problem in neonatal period } \\
\hline & & 꾹 & $\begin{array}{l}\mathscr{\infty} \\
\frac{\mathbb{0}}{0} \\
\overline{\bar{n}} \\
\frac{0}{0} \\
3 . \\
\frac{0}{0} .\end{array}$ & 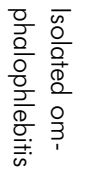 & $\begin{array}{l}\frac{D}{0} \\
\frac{0}{0} \\
\frac{0}{x} \\
\frac{x}{0}\end{array}$ & 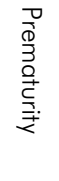 & $\begin{array}{l}\frac{9}{7} \\
\frac{0}{7} \\
\frac{0}{0} \\
\frac{0}{10} \\
\frac{3}{9}\end{array}$ & 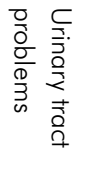 & $\begin{array}{l}\text { D } \\
\text { D } \\
\stackrel{0}{0} \\
3 \\
0 \\
\stackrel{0}{0} .\end{array}$ & 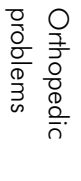 & 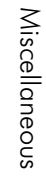 \\
\hline Orthopedic problems & 8 & 1 & 1 & 1 & 1 & & & & & 4 & \\
\hline Growth retardation & 8 & 1 & 3 & & & 1 & 2 & & & & 1 \\
\hline Respiratory tract problems & 5 & 2 & 1 & 1 & & & & & 1 & & \\
\hline Colic & 3 & & 3 & & & & & & & & \\
\hline Euthanasia (fractures) & 2 & & & & & & & & & & \\
\hline Dental problems & 1 & & & & & 1 & & & & & \\
\hline Umbilical hernia & 1 & & & & & 1 & & & & & \\
\hline
\end{tabular}

tis/polyarthritis $(p<0.05$, Figure $2 a)$. Differences in $P M N$ count paralleled leucocyte numbers $(p<0.05$, Figure $2 b)$. Lymphocyte numbers did not differ significantly between groups (Figure 2c). Plasma fibrinogen concentrations were reduced in premature foals born to mares without placentitis and highest in premature foals born after placentitis, in foals with septic arthritis/polyarthritis and, to a lower extent, in foals with an isolated omphalophlebitis (Figure 2d).

Foals with moderate FPT (lgG 400-800 mg/dl, $n=15)$ received $1 \mathrm{~L}$ of hyperimmune serum and foals with severe FPT (IgG $<400 \mathrm{mg} / \mathrm{dl}, \mathrm{n}=5$ ) received $2 \mathrm{~L}$ of hyperimmune serum. Two FPT-foals ( $<12 \mathrm{~h}$ of age) received only colostrum. All foals with septicemia and prematurity not euthanized for poor prognosis received hyperimmune serum ( 33 foals $1 \mathrm{~L}, 16$ foals $2 \mathrm{~L}$ ). Three foals each with asphyxia, gastro-intestinal problems and other problems also received 1 or $2 \mathrm{~L}$ of hyperimmune serum.

\section{Development of foals after dismissal from the clinic}

Owners from all surviving foals treated between 2004 and 2007 (83 out of 128 foals) in 2010 were interviewed by telephone on development of their foals until the age of at least 3 years. Out of these, 70 owners provided the requested information. From the 70 horses, 42 had been healthy during at least 3-years after successful treatment in the neonatal period. A variety of problems were reported in the remaining 28 foals (Table 4).

\section{Discussion}

In this study, the frequency of neonatal disorders in foals, survival rate and further development until the age of at least three years were investigated. Specific questions were whether the spectrum of disorders has changed in comparison to older reports, whether survival rate and subsequent health of the horses has improved and whether Austria-specific characteristics exist.

The distribution of breeds corresponds to breed distribution in the general equine case load in our clinic and presumably also the Austrian horse population. Distribution of foals by gender did not reveal any overall difference. Meconium impaction tended to affect male foals more often than females and all cases requiring surgery were male. Although statistical signficance for gender distribution was not reached, this confirms studies on larger numbers of cases (Pusterla et al. 2004). Also in the group of septicemic foals tended to be more colts than fillies which confirms previous studies (Baker and Drummond 1986, Freeman and Paradis 1992).

Overall survival rate of foals in our study (64\%) is largely in agreement with older studies (54\%: Baker and Drummond 1986; 67\%: Freeman and Paradis 1992, 81\%: Axon et al. 1999). Although direct comparisons between clinics and horse populations may be questioned, the data indicate at least that survival of problem equine neonates has not increased dramatically in recent years.

The most frequent problems in neonatal foals of our study were septicemia and FPT. Compared to older studies, the importance of neonatal septicemia and FPT as risk factor for septicemia has not changed. Also, the situation in Austria does not differ from countries with a more intensive horse breeding industry (Baker and Drummond 1986, Freeman and Paradis 1992, Hoffman and Staempfli 1992). The high number of foals brought to our clinic with FPT only, i.e. before clinical symptoms became overt, indicates that many breeders are well aware of the fact that foals which do not receive adequate amounts of colostrum are at risk to develop septicemia. This is further supported by $>50 \%$ of foals with contracted tendons showing also FPT or septicemia. Foals with contracted tendons were mainly brought to the clinic because they were not able to stand up for suckling.

Survival rate in septicemic foals was $>50 \%$. Although others give a comparable range (Axon et al. 1999, Freeman and Paradis 1992, Gayle et al. 1998, Peek et al. 2004), also much lower survival rates have been reported (25\%: Baker and Drummond 1986; 10\%: Hoffman and Staempfli 1992). This may be due to the fact that many foals in our study were referred to the clinic on the first day of life, i.e. at an early stage and before organ manifestations had occurred. Differences between studies may also be in part caused by different 
classification criteria. Premature foals with septicemia were given the primary diagnosis prematurity. The good survival rate in mature septicemic foals thus must be seen in conjunction with a low survival chance in premature foals. All foals diagnosed with FPT survived. If treatment including hyperimmune serum infusion is initiated rapidly, the development of septicemia can be prevented with good success.

Prematures foals were the second frequent group in our study and the group with the lowest survival rate. Placentitis has been reported as an important reason for premature delivery in mares (Giles et al., 1993). In contrast, in our study, the clear majority of premature foals was born to mares without placentitis. Survival rate in premature foals is low $10-20 \%$, Koterba 1990b) although higher survival rates have also been reported (up to 75\%, Axon et al., 1999). However, horse breeders in Austria are usually not willing to invest in sophisticated neonatal intensive care as provided by a limited number of equine hospitals. Such a treatment might have led to the survival of a few of the foals that died or had to be euthanized in our study.

Clinical and laboratory parameters were not as dramatically changed from normal as expected. This may be due to initial treatment on the farm by the referring veterinarian in many cases. Initial therapy often included NSAID thus masking an initially elevated body temperature. Pronounced deviations from normal values were mainly found in premature foals (e.g. decreased body temperature, prolonged capillary refill time, immature blood count) while - as could be expected fibrinogen was increased in association with prolonged inflammatory alterations (e.g. placentitis in mares, omphalophlebitis, arthritis/polyarthritis). The laboratory parameters investigated are thus helpful for diagnosis of prematurity and assessment of prolonged, localized inflammatory processes. For diagnosis of many other neonatal problems they are of limited value. Clinical parameters are strongly influenced by age of the foal and pretreatment. Although they provide valuable information on individual cases, they are difficult to group for retrospective analysis.

Information on long-term outcome could be obtained for 70 foals. Two of these had been euthanized for fractures occurring on pasture, i.e. for reasons not related to neonatal diseases. Long-term survival of the foals in our study (97\%) was thus good and in the same range as reported by other authors (90\%: Axon and Palmer 1999, 83\%: Freeman and Paradis 1992, 84-93\%: Koterba 1987). However, out of the 68 surviving cases, only 42 horses had been healthy for at least the first three years of life. Foals with FPT, septicemia prematurity and orthopedic problems tended to be affected by further problems more often than those with other problems in the neonatal period. A causality between neonatal diseases and subsequent problems in young horses could not be investigated but cannot be excluded in all cases. In conclusion, with critical evaluation of the foals ' prognosis shortly after hospital admission and preparedness to consider also euthanasia as one option (i.e. strict selection of foals worth an expensive treatment), prognosis for future development of surviving foals is relatively good.

\section{References}

Axon J., Palmer J. and Wilkins P. (1999) Short- and long-term athletic outcome of neonatal intensive care unit survivors. Proc. Am. Assoc. Equine Pract. 45, 224-226

Baker S. and Drummond W. H. (1986) Follow-up evaluation of horses after neonatal intensive care. J. Am. Vet. Med. Assoc. 11, 1454-1457

Freeman L. and Paradis M. R. (1992) Evaluating the effectiveness of equine neonatal care. Vet. Med. 87, 921-926

Gayle J. M., Cohen N. D. and Chaffin M. K. (1998) Factors associated with survival in septicemic foals: 65 cases (1988-1995). J. Vet. Int. Med. 12, 140-146

Giles R. C., Donahue J. M., Hong C. B., Tuttle P. A., Petrites-Murphy M. B., Poonacha K. B., Roberts A. W., Tramontin R. R., Smith B. and Swerczek T. W. (1993) Causes of abortion, stillbirth, and perinatal death in horses: 3527 cases (1986-1991). J. Am. Vet. Med. Assoc 203, $1170-1175$

Hoffman A. M. and Staempfli H. R. (1992) Prognostic variables for survival of neonatal foals under intensive care. J. Vet. Int. Med. 6, 89-95

Koterba A. M. (1987) Equine neonatal intensive care at the University of Florida 1982-1987. An update. Proc. Am. Assoc. Equine Pract. 33, 805-816

Koterba A. M. and Brewer B. D. (1984) Clinical and clinicopathological characteristics of the septicemic neonatal foal: review of 38 cases. Equine Vet. J. 16, 376-383

Koterba A. M. (1990a) Physical Examination. In: Equine Clinical Neonatology. Koterba A. M., Drummond W. H., Kosch P, Lea and Febiger, Philadelphia, USA, 71-83

Koterba A. M. (1990b) Prematurity In: Equine Clinical Neonatology. Koterba A. M., Drummond W. H., Kosch P, Lea and Febiger, Philadelphia, USA, 769-778

LeBlanc M. M, Tran T. and Baldwin J. L. (1992) Factors that influence passive transfer of immunoglobulins in foals. J. Am. Vet. Med. Assoc. 00, 179-183

McLaughlin B. G., Doige C. E. and McLaughlin P. S. (1986) Thyroid hormone levels in foals with congenital musculosceletal lesions. Can. Vet. J. 27, 264-267

Peek S. F., Darien B. J., Semrad S. D., McGuirk S., Lien L., Riseberg A., Slack J. A. and Coombs D. (2004) A prospective study of neonatal septicemia and factors influencing survival. Proc. Am. Assoc. Equine Pract. 50

Pusterla N., Magdesian K., Maleski K., Spier J. and Madigan J. E. (2004) Retrospective evaluation of the use of acetylcysteine enemas in the treatment of meconium retention in foals: 44 cases (1987-2002). Equine Vet. Educ. 16, 133

Sanchez L. C. (2005) Equine neonatal sepsis. Vet. Clin. N. Am. Equine Pract. 21, 273-293

Dr. Franziska Palm, Dipl. ECAR

Section for Obstetrics, Gynecology and Andrology

University of Veterinary Sciences

Veterinärplatz 1

1210 Vienna

Austria

franziska.palm@vetmeduni.ac.at 